\title{
Evaluation of Hypolipidemic and TNF- $\alpha$ Lowering Effect of Ficus Religiosa in Dyslipidemic Wistar Rats
}

\author{
Priyanka Rathi ${ }^{1}$, Rajendra Nath ${ }^{2 *}$, KK Pant ${ }^{2}$, RK Dixit ${ }^{2}$, Rishi Pal ${ }^{2}$ and Rahul Kumar ${ }^{2}$ \\ 1Department of Pharmacology, Rajasthan University of Health Sciences CMS, India \\ 2Department of Pharmacology \& Therapeutics, K G's Medical University, India
}

Submission: May 01, 2019; Published: May 28, 2019

*Corresponding author: Rajendra Nath, Pharmacology \& Therapeutics, K G’s Medical University, Lucknow (UP), 226003, India

Abstract

Objective: To evaluate the Tumor necrosis factor- $\alpha$ (TNF- $\alpha$ ) lowering and hypolipidemic effects of Ficus religiosa in high fat diet induced dyslipidemic rats. As there is no satisfactory and safe treatment option for dyslipidemia, a major risk factor for cardiovascular diseases, derivatives from medicinal plants can be a good alternative for its treatment.

Methods: 30 male adult wistar rats were divided into 5 groups $(n=6)$ and were fed with high fat diet (HFD) for 6 weeks to induce hyperlipidemia. After the induction period, rats in groups II-IV were treated with Ficus religiosa 100, 200, and $400 \mathrm{mg} / \mathrm{kg}$ body weight respectively and group V with atorvastatin $40 \mathrm{mg} / \mathrm{kg}$ body weight orally for 4 weeks. Plasma Tumor necrosis factor- $\alpha$ and plasma lipid profile levels were measured for evaluation.

Results: The results demonstrate that all three doses of Ficus religiosa have an effective curative effect against the elevated total cholesterol (TC), triglycerides (TG) , low density lipoproteins (LDL) and lowering of Tumor necrosis factor - $\alpha$ levels with significant effect at $400 \mathrm{mg} / \mathrm{kg}$ dose which includes high density lipoproteins (HDL) improving effect.

Conclusion: The results of the present study are encouraging and may reveal the importance of Ficus religiosa as an economical antihyperlipidemic agent.

Keywords: Atorvastatin; Hyperlipidemia; HFD; LDL; HDL; Antihyperlipidemic agent; Lipid profile levels; Body weight; Dyslipidemia; Cardiovascular morbidity; Antimicrobial; Antifungal; Immune modulator; Antioxidant; Hypoglycemic, Hypolipidemic; Antihelmintics; Wound healing properties

Abbreviations: TNF- $\alpha$ : Tumor Necrosis Factor- $\alpha$; TC: Total Cholesterol; TG: Triglycerides; LDL: Low Density Lipoproteins; VLDL: Very Low Density Lipoprotein; HDL: High Density Lipoproteins; ELISA: Enzyme-Linked Immune-Sorbent Assay; CPCSEA: Committee for the Purpose of Control and Supervision of Experiments on Animals; IAEC: Institutional Animal Ethical Committee; OECD: Organisation for Economic Cooperation and Development; HFD: High Fat Diet; FR: Ficus religiosa

\section{Introduction}

Dyslipidemia is one of the major risk factors for the development of cardiovascular morbidity and accounts for more than half the global cases of ischemic heart disease causing more than 4 million deaths per year [1]. Evidences from epidemiologic, pathologic and metabolic studies strongly support a causal relationship between serum concentration of lipoprotein and atherosclerosis and its related complications, such as stroke and myocardial infarction [2,3]. Dyslipidemia is also a well-recognized risk factor for the development of insulin resistance and the metabolic syndrome [4].

The successful treatment of dyslipidemia has shown to substantially reduce morbidity and mortality in dyslipidemic subjects as compared to non-treated dyslipidemic controls [57]. Conventionally, dyslipidemia is managed with drugs like Hydroxy Methyl Glutaryl Coenzyme-A reductase inhibitors (Statins), fibric acid derivatives, bile acid sequestrants, niacin etc [8]. However, modern allopathic drugs, in general have not been a concrete solution till date, because commonly used hypolipidemic drugs are costly and have inadvertently produced serious adverse effects [9]. It is therefore evident to look for options and switch on to safer indigenous system of medicine and to harvest medicinal plants having multiple beneficial effects which can take care of most of the metabolic abnormalities associated with dyslipidemia [10]. 
Ficus religiosa commonly known as Bo or peepal tree (belongs to the Moraceae, the fig or mulberry family), is a large perennial tree that grows throughout India and south-east Asia, especially in the vicinity of temples. Preliminary phytochemical screening of Ficus religiosa barks has shown the presence of tannins, saponins, flavonoids, steroids, terpenoids, cardiac glycosides, bergapten, bergaptol, lanosterol, $\beta$-sitosterol, stigmasterol, lupen-3-one, $\beta$-sitosterol-d-glucoside (phytosterolin), and vitamin K1 [11]. Numerous studies have reported Ficus religiosa to exhibit antimicrobial., antifungal., immune-modulator, antioxidant, hypoglycemic, hypolipidemic, antihelmintics, and wound healing properties [12]. Apart from these few preliminary studies $[13,14]$, the plant has not been widely studied for its hypolipidemic effects. The current study, therefore, was envisaged to investigate the TNF- $\alpha$ lowering and hypolipidemic effects of Ficus religiosa in high fat diet induced dyslipidemic rat models in order to rationalize its medicinal use in dyslipidemia.

\section{Materials \& Methods}

\section{Drugs}

Ficus religiosa (FR) powder was procured from Vyas Pharmaceuticals, Indore of same batch. It was administered orally in three doses of 100 [13,14], 200 [14], and $400 \mathrm{mg} / \mathrm{kg}$ body weight. We used the purified dried powder form as powder form, usually contains most of the active compounds and is a safer form to consume as compared to other forms, like extract. Since the oral route is the usual and convenient method of taking a drug and does not need any kind of assistance which ensures better patient compliance, therefore the oral route was chosen for giving the test drug.

Tab. Atorvastatin in an oral dose of $40 \mathrm{mg} / \mathrm{kg}$ body weight [15] was used as the standard drug.

\section{Diagnostic kits}

For the estimation of plasma TNF- $\alpha$ level, AviBion TNF- $\alpha$ ELISA (enzyme-linked immune-sorbent assay) kit was used which was procured from Orgenium Laboratories Business Unit, Finland. For the estimation of plasma Total Cholesterol, high density lipoprotein (HDL), and Triglyceride levels, commercial kits (based on enzymatic assay method, manufactured by Analyticon Biotechnologies AG, Germany) and a fully automated clinical chemistry analyzer (Biolyzer 200, manufactured by Analyticon Biotechnologies AG, Germany) were used.

\section{Experimental animals}

Thirty (30) healthy male adult wistar rats of age between 12 to 14 weeks, weighing between 140-160 grams and bred in the CPCSEA (Committee for the Purpose of Control and Supervision of Experiments on Animals) certified animal house at IITR (Indian Institute of Toxicology Research, Lucknow) were used in the study. They were housed in well-ventilated Institutional Animal House Facility of King George's Medical University, Lucknow under standard laboratory condition of temperature and humidity $\left(25 \pm 2{ }^{\circ} \mathrm{C}, 70 \%\right)$. They were provided high fat pellet diet and water ad libitum with 12 hours light/ dark cycle.

The use of these animals and the experimental protocol was approved by the Institutional Animal Ethical Committee (IAEC), King George's Medical University, Lucknow and registered under Registration No. 646/02/a//CPCSEA (India) for conducting animal tissue experiment. Care of animals was taken as per internationally accepted guidelines of the CPCSEA (Committee for the Purpose of Control and Supervision of Experiments on Animals).

\section{Diet}

High fat diet (HFD) [16-18] having following constituents was used (Table 1):

Table 1: Protein ${ }^{*}$ - Casein; Fat ${ }^{* *}$ : High Fat Pellet Diet - Rice bran oil + Soy oil +Butter oil (in 1:1:15 proportion) containing Saturated fatty acids \& Unsaturated fatty acids (Monounsaturated fatty acids-MUFA + Polyunsaturated fatty acids-PUFA in 2:3 proportion); Carbohydrate*** Corn Starch + Sucrose + Malodextrin

\begin{tabular}{|c|c|c|}
\hline & Ingredients & High Fat Pellet Diet \\
\hline 1 & Protein* $^{*}$ & $16 \%$ \\
\hline 2 & Fat** $^{* *}$ & $21 \%$ \\
\hline 3 & Carbohydrate*** $^{*}$ & $48 \%$ \\
\hline 4 & Crude Fibre & $3 \%$ \\
\hline 5 & Acid Insoluble Ash & $2.30 \%$ \\
\hline 6 & Vitamins \& Minerals & Approximate quantity \\
\hline 7 & Moisture & $8 \%$ \\
\hline
\end{tabular}

It was manufactured and supplied by Dayal Industries Pvt. Ltd. Barabanki Road, Lucknow, Uttar Pradesh.

\section{Acute toxicity study of Ficus religiosa}

Toxicity studies to determine the safe oral dose of Ficus religiosa was not done in our study because acute toxicity tests, as per Organisation for Economic Co-operation and Development (OECD) 423 guidelines (2010) have already been conducted in many previous studies Khan et al. [19].

\section{Experimental protocol}

After one week of acclimatization, rats were randomly divided into 5 groups. Baseline body weight of all rats was recorded, and baseline biochemical estimation of plasma TNF- $\alpha$ levels and plasma lipid profile was done. Rats in all 5 groups were then given an HFD and water ad libitum for 6 weeks for induction of dyslipidemia. At the end of 6th week, body weight of all rats was recorded and biochemical analysis of plasma TNF- $\alpha$ level and lipid profile was done. Rats were then given the following treatment for 4 weeks:

a) Group I $(n=6)$; dyslipidemia control group: Distilled water + HFD

b) Group II $(\mathrm{n}=6): 100 \mathrm{mg} / \mathrm{kg}$ body weight Ficus religiosa + HFD 


\section{Current Research in Diabetes \& Obesity Journal}

c) Group III $(\mathrm{n}=6): 200 \mathrm{mg} / \mathrm{kg}$ body weight Ficus religiosa + HFD

d) Group IV (n=6): $400 \mathrm{mg} / \mathrm{kg}$ body weight Ficus religiosa + HFD

e) Group V $(\mathrm{n}=6): 40 \mathrm{mg} / \mathrm{kg}$ body weight Atorvastatin + HFD
Both the drugs were formulated as suspension using distilled water just prior to administration. The strength of the suspension was adjusted in a way that $1 \mathrm{ml}$ of suspension contained the desired dose that was to be administered in an individual rat. The drugs were given once daily (at 10 a.m. in the morning) orally with the help of a feeding cannula. At the end of treatment, body weight was recorded, and a blood sample was withdrawn for biochemical analysis (Figure 1).

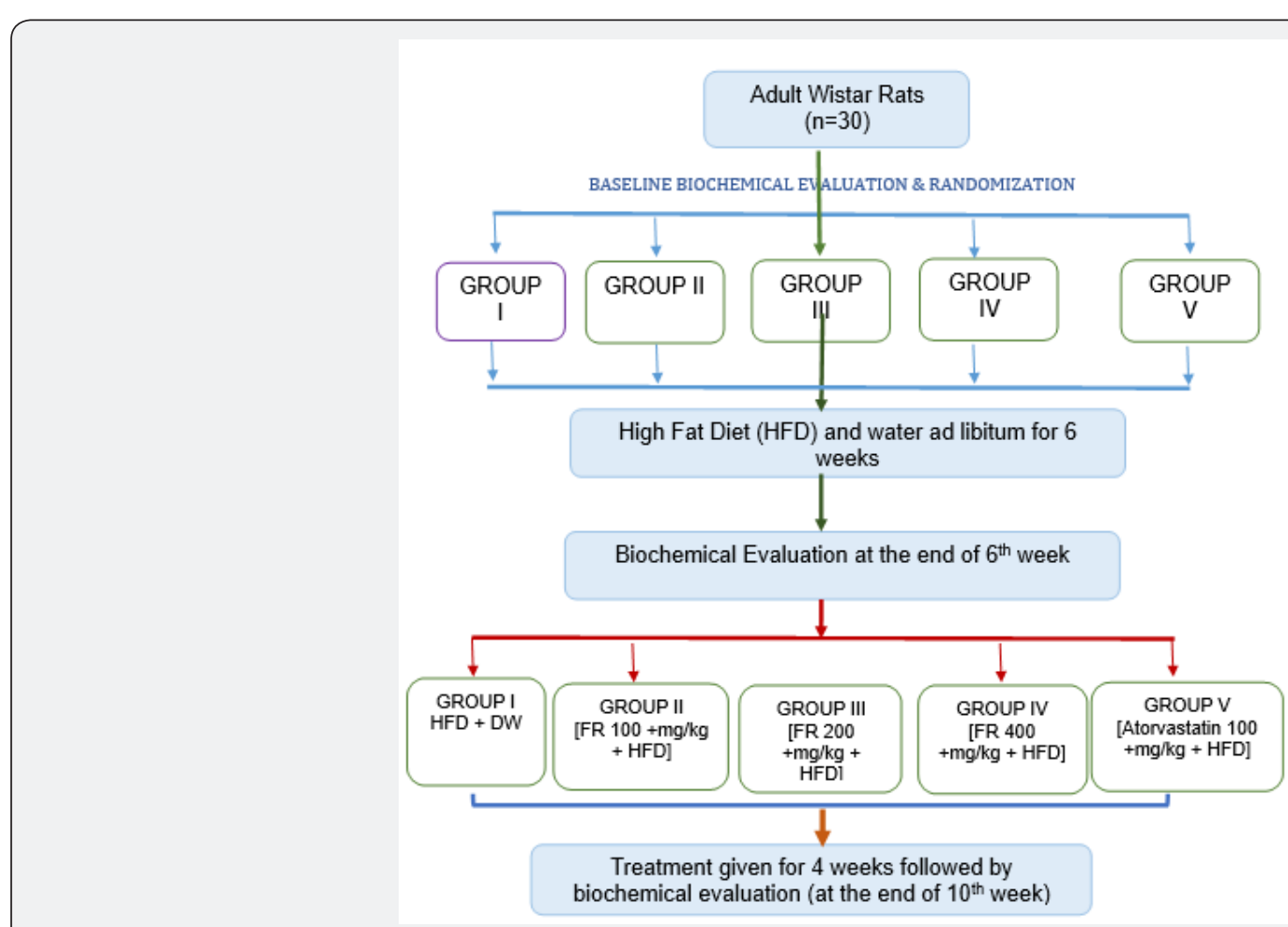

HFD: High Fat Diet; DW: Distilled Water; FR: Ficus religiosa; mg/kg: Milligram/Kilogram

Figure I: Flow diagram depicting the experimental protocol.

\section{Sample collection and preparation}

Blood sample of $1 \mathrm{ml}$ volume was withdrawn from overnight fasted rats through retro- orbital route. An intraperitoneal injection of pentobarbitone in a dose of $35 \mathrm{mg} / \mathrm{kg}$ was used for producing light anesthesia during the procedure. The sample was left at room temperature for $30 \mathrm{~min}$ for coagulation and plasma was then separated by centrifuging the sample at a rate of 2000 r.p.m. (rate per minute) for 15 minutes. The separated plasma was then stored at $-20^{\circ} \mathrm{C}$ (degree Celsius) until use.

\section{Biochemical analysis}

The biochemical analysis of the sample for estimation of plasma TNF- $\alpha$ level and lipid profile was done in the Department of Pathology, King George's Medical University, Lucknow.

Estimation of TNF- $\alpha$ : The plasma TNF- $\alpha$ level was estimated by an enzyme-linked immune-sorbent assay (ELISA) using a commercial TNF- $\alpha$ ELISA kit.

Estimation of plasma lipid profile: Plasma TC, HDL, and TG levels were estimated using commercial kits and a fully automated clinical chemistry analyzer (Biolyzer 200). LDL levels were calculated using the Fried Ewald Formula [15]: i.e. LDL = TC- [HDL + TG/ 5]. very low-density lipoprotein (VLDL) level was also calculated using the Friedewald Formula: VLDL $=\mathrm{TG}$ $/ 5$.

\section{Statistical analysis}

All data were expressed as mean \pm SD. The data were analyzed by one-way analysis of variance (ANOVA). Independent t test/ Tuke's pair wise comparison was used for comparison between the treatment groups. Differences in treatment effects within treatment groups and between the treatment and control groups were tested by a multivariate analysis of variance repeated-measures design. $\mathrm{p}$ value $<0.05$ was considered as statistically significant.

\section{Results}

The baseline (day 0), week 6, and week 10 (post-treatment) values of fasting plasma TNF- $\alpha$ and fasting plasma lipid profile are summarized in Table 2. 


\section{Current Research in Diabetes \& Obesity Journal}

Table 2: Fasting plasma TNF- $\alpha$ level (picogram/millilitre) and fasting plasma lipid profile (milligram/decilitre) summary (mean $\pm S D$ )

\begin{tabular}{|c|c|c|c|c|c|c|c|}
\hline \multirow{2}{*}{ Variables } & \multirow{2}{*}{$\begin{array}{c}\text { Groups } \\
(n=6)\end{array}$} & \multicolumn{3}{|c|}{ Periods } & \multirow{2}{*}{$\begin{array}{c}\text { Baseline to } 6 \\
\text { Weeks p Value }\end{array}$} & \multicolumn{2}{|c|}{6 Weeks to 10 Weeks } \\
\hline & & Baseline (Day 0) & Week 6 & Week 10 (Post-Treatment) & & $\%$ Mean Change & p-Value1 \\
\hline \multirow{5}{*}{$\begin{array}{l}\text { TNF- } \alpha(\mathrm{pg} / \\
\mathrm{ml})\end{array}$} & I & $5.5 \pm 1.8$ & $7.6 \pm 1.3$ & $9.9 \pm 1.0$ & $0.002^{*}$ & 41.48 & $0.02^{*}$ \\
\hline & II & $5.5 \pm 2.0$ & $5.3 \pm 0.4$ & $5.7 \pm 1.9$ & 0.88 & -7.69 & 0.69 \\
\hline & III & $4.7 \pm 1.0$ & $5.7 \pm 1.5$ & $4.7 \pm 1.8$ & 0.11 & -12.22 & 0.36 \\
\hline & IV & $4.7 \pm 1.4$ & $5.1 \pm 0.7$ & $4.0 \pm 1.0$ & $0.01^{*}$ & -18.67 & 0.17 \\
\hline & $\mathrm{V}$ & $6.0 \pm 2.2$ & $7.4 \pm 2.2$ & $5.7 \pm 1.4$ & $0.001^{*}$ & -13.8 & 0.26 \\
\hline \multirow{5}{*}{$\begin{array}{c}\text { Total } \\
\text { Cholesterol } \\
\text { (mg/ dl) }\end{array}$} & I & $51.3 \pm 3.0$ & $89.8 \pm 6.3$ & $101.7 \pm 1.6$ & $0.001^{*}$ & 13.64 & $0.01^{*}$ \\
\hline & II & $51.3 \pm 8.5$ & $93.9 \pm 3.6$ & $70.9 \pm 2.4$ & $<0.0001^{*}$ & -24.47 & $<0.0001^{*}$ \\
\hline & III & $52.7 \pm 9.8$ & $86.0 \pm 14.3$ & $61.4 \pm 1.8$ & $0.01^{*}$ & -27.23 & $0.006^{*}$ \\
\hline & IV & $47.9 \pm 5.2$ & $99.3 \pm 11.2$ & $47.6 \pm 1.3$ & $0.001^{*}$ & -51.62 & $<0.0001^{*}$ \\
\hline & $\mathrm{V}$ & $48.1 \pm 4.0$ & $89.9 \pm 8.9$ & $47.6 \pm 1.5$ & $<0.0001^{*}$ & -46.8 & $<0.0001^{*}$ \\
\hline \multirow{5}{*}{$\begin{array}{l}\text { Triglyceride } \\
\text { (mg/dl) }\end{array}$} & I & $29.5 \pm 1.5$ & $68.3 \pm 4.8$ & $102.1 \pm 3.4$ & $<0.0001^{*}$ & 50.22 & $<0.0001^{*}$ \\
\hline & II & $40.1 \pm 3.1$ & $89.7 \pm 2.1$ & $74.4 \pm 4.4$ & $<0.0001^{*}$ & -17.08 & $<0.0001^{*}$ \\
\hline & III & $35.1 \pm 3.0$ & $74.8 \pm 1.0$ & $51.7 \pm 2.5$ & $<0.0001^{*}$ & -30.89 & $<0.0001^{*}$ \\
\hline & IV & $23.7 \pm 3.7$ & $57.5 \pm 3.8$ & $32.9 \pm 2.6$ & $<0.0001^{*}$ & -42.6 & $<0.0001^{*}$ \\
\hline & V & $20.4 \pm 3.0$ & $61.5 \pm 2.3$ & $27.5 \pm 1.9$ & $<0.0001^{*}$ & -55.21 & $<0.0001^{*}$ \\
\hline \multirow{5}{*}{$\begin{array}{l}\text { HDL (mg/ } \\
\text { dl) }\end{array}$} & I & $36.0 \pm 6.5$ & $31.9 \pm 4.6$ & $29.0 \pm 0.7$ & 0.31 & -7.55 & 0.19 \\
\hline & II & $28.4 \pm 7.0$ & $27.3 \pm 1.6$ & $34.3 \pm 2.0$ & 0.73 & 4.19 & 0.14 \\
\hline & III & $34.3 \pm 4.3$ & $33.6 \pm 3.2$ & $36.8 \pm 1.7$ & 0.72 & 10.39 & 0.09 \\
\hline & IV & $32.6 \pm 3.3$ & $29.1 \pm 1.8$ & $37.8 \pm 2.0$ & $0.04^{*}$ & 28.9 & $0.003^{*}$ \\
\hline & V & $33.1 \pm 4.5$ & $30.1 \pm 1.6$ & $37.3 \pm 3.1$ & 0.19 & 24.41 & $0.007^{*}$ \\
\hline \multirow{5}{*}{$\begin{array}{l}\text { LDL (mg/ } \\
\text { dl) }\end{array}$} & I & $12.5 \pm 1.6$ & $17.2 \pm 1.6$ & $23.3 \pm 1.9$ & $0.002^{*}$ & 37 & $0.01^{*}$ \\
\hline & II & $17.9 \pm 6.7$ & $22.6 \pm 6.6$ & $22.7 \pm 2.9$ & 0.21 & 5.98 & 0.96 \\
\hline & III & $15.8 \pm 8.0$ & $24.1 \pm 6.1$ & $20.3 \pm 3.8$ & 0.11 & -12.27 & 0.19 \\
\hline & IV & $12.7 \pm 4.5$ & $25.8 \pm 5.8$ & $22.2 \pm 3.8$ & $0.01^{*}$ & -10.77 & 0.26 \\
\hline & V & $14.3 \pm 6.7$ & $24.2 \pm 4.7$ & $20.7 \pm 1.0$ & $0.01^{*}$ & -12.21 & 0.11 \\
\hline \multirow{5}{*}{$\begin{array}{l}\text { Very Low- } \\
\text { Density } \\
\text { Lipoprotein } \\
(\mathrm{mg} / \mathrm{dl})\end{array}$} & I & $5.9 \pm 0.3$ & $13.7 \pm 1.0$ & $20.4 \pm 0.7$ & $<0.0001^{*}$ & 50.22 & $<0.0001^{*}$ \\
\hline & II & $8.0 \pm 0.1$ & $18.0 \pm 0.4$ & $14.9 \pm 0.9$ & $<0.0001^{*}$ & -17.07 & $<0.0001^{*}$ \\
\hline & III & $7.0 \pm 0.6$ & $15.0 \pm 0.2$ & $10.3 \pm 0.5$ & $<0.0001^{*}$ & -30.89 & $<0.0001^{*}$ \\
\hline & IV & $4.7 \pm 0.7$ & $11.5 \pm 0.8$ & $6.6 \pm 0.5$ & $<0.0001^{*}$ & -42.6 & $<0.0001^{*}$ \\
\hline & V & $4.1 \pm 0.6$ & $12.3 \pm 0.5$ & $5.5 \pm 0.4$ & $<0.0001^{*}$ & -55.21 & $<0.0001^{*}$ \\
\hline
\end{tabular}

Table 3: Significance of fasting plasma TNF- $\alpha$ (picogram/millilitre) and fasting plasma lipid profile (milligram /decilitre) summary (mean $\pm S D$ ).

\begin{tabular}{|c|c|c|c|c|c|c|}
\hline \multirow{2}{*}{ Variables } & \multicolumn{2}{|c|}{ Groups } & \multicolumn{2}{c|}{ Baseline } & \multicolumn{2}{c|}{ Week 10 } \\
\cline { 3 - 7 } & & Mean Difference & p-Value & Mean Difference & p-Value1 \\
\hline \multirow{3}{*}{ TNF- $\alpha(\mathrm{pg} / \mathrm{dl})$} & \multirow{3}{*}{ Group I vs } & II & 0.01 & 1 & 4.91 & $<0.0001^{*}$ \\
\cline { 3 - 7 } & & III & 0.78 & 0.99 & 5.2 & $<0.0001^{*}$ \\
\cline { 3 - 7 } & & IV & 0.75 & 0.99 & 4.19 & $<0.0001^{*}$ \\
\cline { 3 - 7 } & & V & 0.49 & 1 & $<0.0001^{*}$ \\
\hline
\end{tabular}




\section{Current Research in Diabetes \& Obesity Journal}

\begin{tabular}{|c|c|c|c|c|c|c|}
\hline \multirow{4}{*}{$\begin{array}{l}\text { Total Cholesterol } \\
\text { (mg/dl) }\end{array}$} & \multirow{4}{*}{ Group I vs } & II & 0.05 & 1 & 30.82 & $<0.0001^{*}$ \\
\hline & & III & 1.38 & 1 & 40.32 & $<0.0001^{*}$ \\
\hline & & IV & 3.44 & 0.98 & 54.14 & $<0.0001^{*}$ \\
\hline & & $\mathrm{V}$ & 3.18 & 0.99 & 54.16 & $<0.0001^{*}$ \\
\hline \multirow{4}{*}{$\begin{array}{l}\text { Triglyceride (mg/ } \\
\text { dl) }\end{array}$} & \multirow{4}{*}{ Group I vs } & II & 16.37 & 0.07 & 27.67 & $<0.0001^{*}$ \\
\hline & & III & 5.69 & 0.06 & 50.4 & $<0.0001^{*}$ \\
\hline & & IV & 5.85 & 0.05 & 69.14 & $<0.0001^{*}$ \\
\hline & & $\mathrm{V}$ & 9.05 & 0.06 & 74.55 & $<0.0001^{*}$ \\
\hline \multirow{4}{*}{ HDL (mg/dl) } & \multirow{4}{*}{ Group I vs } & II & 7.56 & 0.22 & 5.3 & $0.03^{*}$ \\
\hline & & III & 1.68 & 1 & 7.79 & $<0.0001^{*}$ \\
\hline & & IV & 3.45 & 0.94 & 8.74 & $<0.0001^{*}$ \\
\hline & & $\mathrm{V}$ & 2.86 & 0.98 & 8.27 & $<0.0001^{*}$ \\
\hline \multirow{4}{*}{ LDL (mg/dl) } & \multirow{4}{*}{ Group I vs } & II & 5.45 & 0.6 & 0.57 & 1 \\
\hline & & III & 3.31 & 0.97 & 2.96 & 0.85 \\
\hline & & IV & 0.2 & 1 & 1.07 & 1 \\
\hline & & $\mathrm{V}$ & 1.8 & 1 & 2.61 & 0.92 \\
\hline \multirow{4}{*}{$\begin{array}{l}\text { Very Low-Density } \\
\text { Lipoprotein (mg/ } \\
\text { dl) }\end{array}$} & \multirow{4}{*}{ Group I vs } & II & 2.27 & 0.65 & 5.53 & $<0.0001^{*}$ \\
\hline & & III & 1.13 & 0.06 & 10.08 & $<0.0001^{*}$ \\
\hline & & IV & 1.17 & 0.05 & 13.82 & $<0.0001^{*}$ \\
\hline & & $\mathrm{V}$ & 1.81 & 0.05 & 14.9 & $<0.0001^{*}$ \\
\hline
\end{tabular}

\section{Within groups}

The significance of mean difference of plasma TNF- $\alpha$ and plasma lipid profile within five groups at baseline (day 0) and at week 10 are summarized in Table 3 and shown graphically in Figure 2a.

\section{Discussion}

The present study was conducted to discern the effect of Ficus religiosa in lowering elevated plasma TNF- $\alpha$ levels and dyslipidemia in hyperlipidemic adult Wistar rats. These effects were compared with standard drug Atorvastatin. Plasma TNF- $\alpha$ levels were evaluated in our study because previous studies in humans have shown that TNF- $\alpha$ interferes with lipid homeostasis and activates harmful proatherogenic and related pathological processes [20]. The most prominent alteration being decreased HDL, increased LDL, and raised TG [21]. The association between the inflammatory marker TNF- $\alpha$ and lipids have been shown to be a risk factor not only for the development of atherosclerosis but also for cardiovascular disease [22].

In our study, there was no statistically significant difference between the baseline mean values of fasting plasma TNF- $\alpha$ and fasting plasma lipid levels in all five groups. Hence all the groups were matched and comparable to each other ((Table 3 \& Figure 2a-2f).

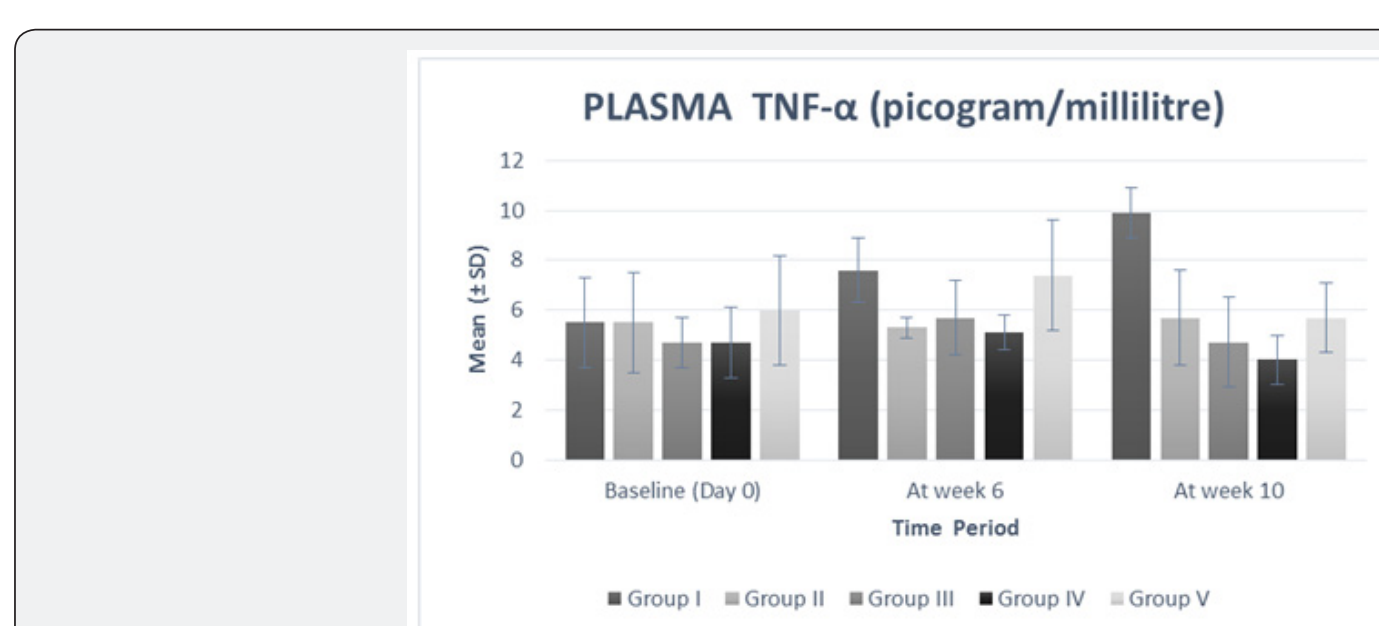

Figure 2a: Pre and post treatment mean $( \pm S D)$ TNF- $\alpha$ levels in 5 groups of rats. 


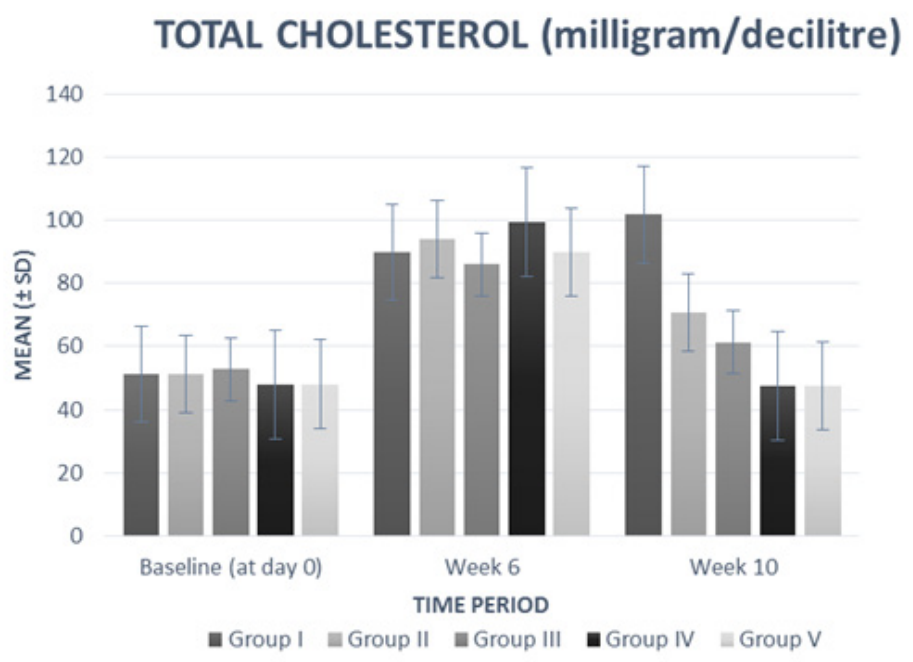

Figure 2b: Pre and post treatment mean $( \pm S D)$ Total Cholesterol levels in 5 groups of rats.

\section{PLASMA TRIGLYCERIDE \\ (milligram/decilitre)}

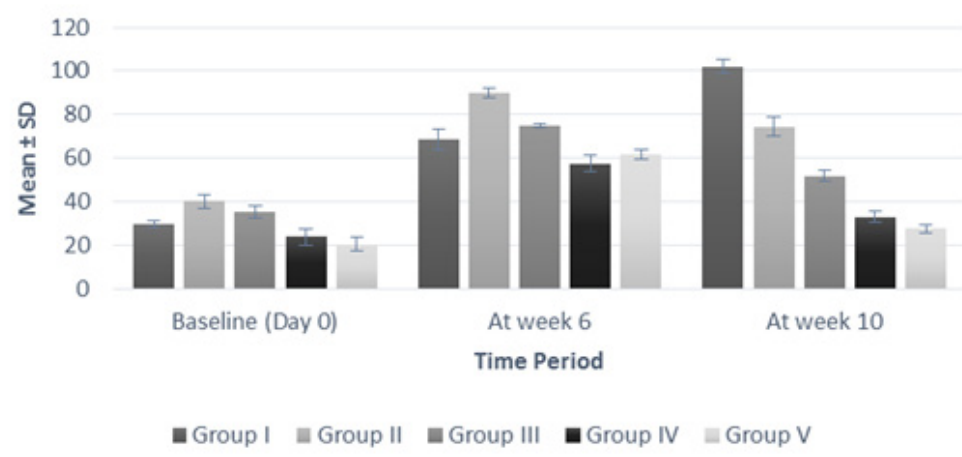

Figure 2c: Pre and post treatment mean ( \pm SD) Triglyceride (TG) levels in 5 groups of rats.

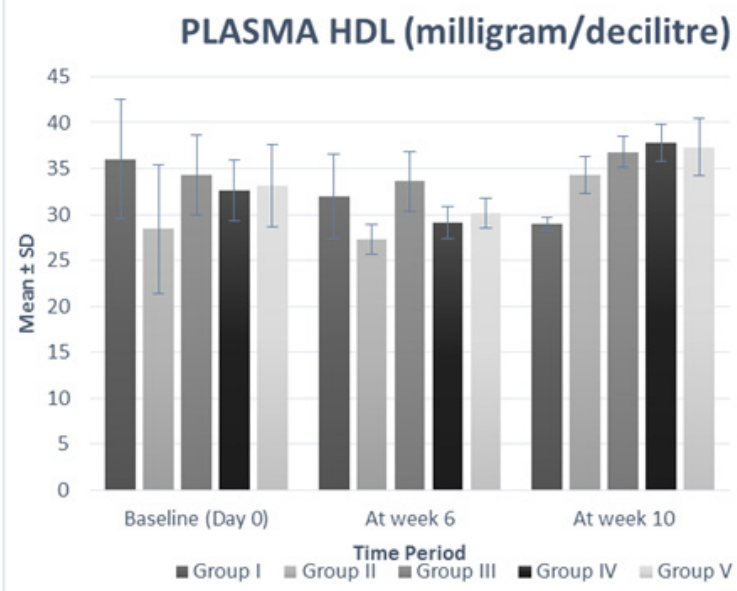

Figure 2d: Pre and post treatment mean $( \pm S D)$ High Density Lipoprotein (HDL) levels in 5 groups of rats. 


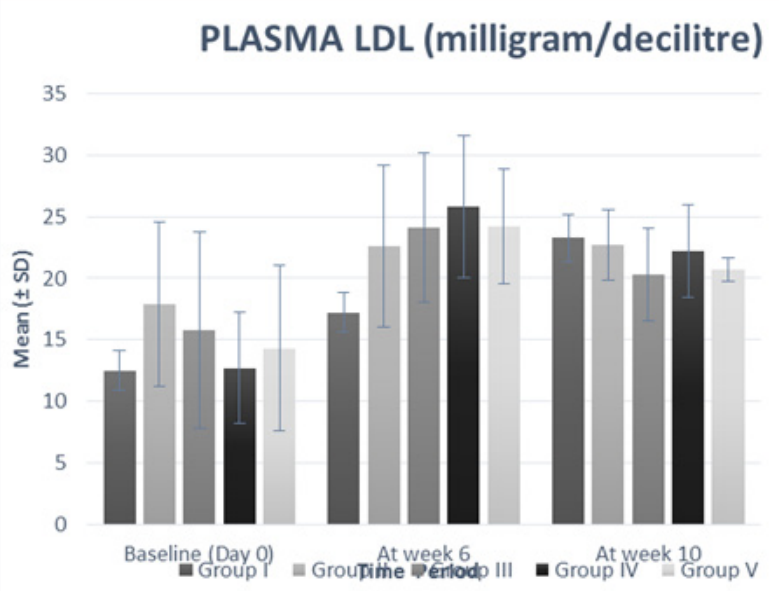

Figure 2e: Pre and post treatment mean $( \pm S D$ ) Low Density Lipoprotein (LDL) levels in 5 groups of rats.

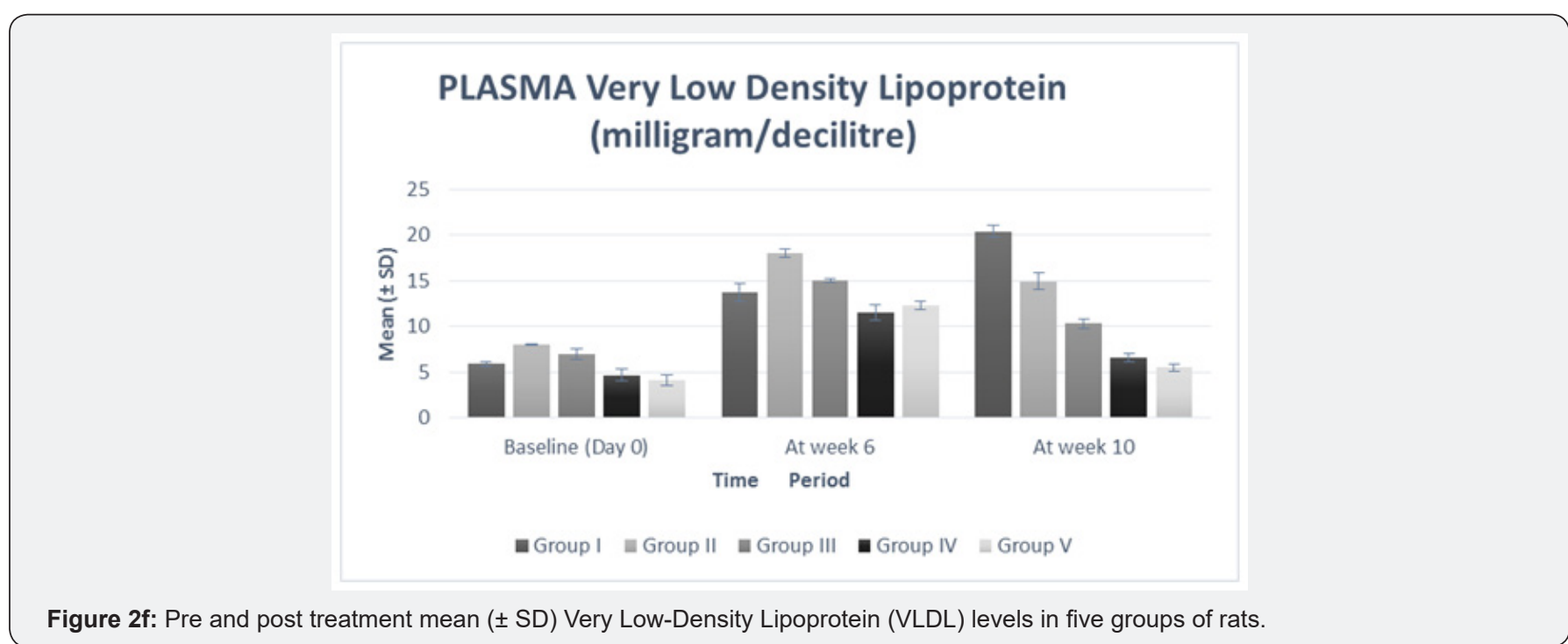

The high fat diet was continued in all the five groups from day 1 to the end of the study. As compared to the values at week 6 , group I showed a statistically significant increase in plasma TNF- $\alpha(p=0.02)$, TC ( $p=0.01), T G(p<0.0001)$, LDL $(p=0.01)$, and VLDL $(\mathrm{p}<0.0001$ ) levels at week 10 (Table 2 \& Figure 2a-2f). These findings suggest that continuation of high fat diet caused a further worsening of serum biochemical parameters which is in accordance with a previous study [23]. Results from our study also confirmed the previously reported associations between lipid profile and inflammatory marker, TNF- $\alpha$ [21,24].

Plasma TNF- $\alpha$ level at week 10 was found to be lower than the values at week 6 in all the treatment groups, i.e. groups II, III, IV, and V. Intergroup comparison analysis showed a dose dependent response with significant mean percent reduction in group IV (-18.67\%) and minimum in group II (-7.69\%) (Table 3 \& Figure 2a).

When compared with the standard drug group (group V) group IV showed a higher percent reduction while that of groups
II and III was less than group V (Table 3 \& Figure 2a). These findings are in agreement with a recent study of Kirana et al. [14] who reported that Ficus religiosa caused a significant reduction in TNF- $\alpha$ level. TNF- $\alpha$ can directly alter lipid metabolism through inhibition of free fatty acid uptake and lipogenesis and stimulate free fatty release via lipolysis and therefore contribute to the development of dyslipidemia and resultant metabolic complications [25]. The lowering of plasma TNF- $\alpha$ level by Ficus religiosa may possibly be one of the mechanism of its lipid lowering action as Ayo P Doumatey et al. [26] has also reported that lack of TNF- $\alpha$ function results in significant reduction in obesity induced hyperlipidemia which would contribute to changes in insulin sensitivity.

The plasma lipid profile at week 10 showed a significant decrease in plasma TC $(\mathrm{p}<0.0001)$, TG $(\mathrm{p}<0.0001)$, and VLDL $(\mathrm{p}<0.0001)$ levels of all the treatment groups, i.e. II, III, IV, V as compared to their respective levels at week 6 (Table 2 \& Figure $2 \mathrm{~b}-2 \mathrm{f})$. This suggests that the treatment given to all the groups 
was effective in lowering the plasma levels of TC, TG, and VLDL. The mean differences in the TC level between the individual treatment groups and the control group (group I) also showed a significant therapeutic effect (mean difference p value $=0.001$ ) in all the treatment groups (Table 3 ).

The inter group comparison revealed that group IV showed a more pronounced percent mean reduction in the abovementioned parameters than group III, which in turn showed a higher mean percent reduction than group II (Figure 2b2f). When compared with the standard drug group, group IV $(-51.62 \%)$ resulted in a higher mean percent reduction in TC level than group V (-46.80\%) (Figure $2 \mathrm{~b})$. These findings suggest that Ficus religiosa in a dose of 400 milligram/kilogram might has a better anti-hypercholesterolemic effect than the standard drug. However, its effect was not better than standard in lowering TG and VLDL levels (Table 3, Figure 2c \& 2d).

These findings are in accordance with a previous study [13] which also reported that Ficus religiosa significantly reduced serum triglycerides and total cholesterol in Streptozotocin induced diabetic rats. This activity might be due to the presence of various phytochemical constituents, the investigation of which is still under progress. The observed hypocholesterolemic and hypotriglyceridemic effect can also be attributed to the activation of the enzyme, lipoprotein lipase. Agarwal \& Chauhan [27] had reported that cellulose and lignin present in Ficus religiosa increases fecal excretion of cholesterol.

HDL levels after 10 weeks were found to be lower in group II as compared to values after 6 weeks, but it was not found to be significant. Although higher values of HDL levels after 10 weeks were observed in group III but it was statistically not significant. Both group IV $(\mathrm{p}=0.003)$ and V $(\mathrm{p}=0.007)$ showed a significant increase in HDL levels after 10 weeks as compared to values after 6 weeks (Table 3 \& Figure 2e).

When compared with group I, the mean difference in HDL levels after 10 weeks between group I and all individual treatment groups was found to be statistically significant $(\mathrm{p}=$ 0.001 ) suggesting a significant beneficial effect in increasing HDL in all the treatment groups.

LDL levels after 10 weeks have shown no significant changes (Table 3 \& Figure 2f). When compared with group I, the mean difference in LDL levels at week 10 between group I and all individual treatment groups was found to be statistically nonsignificant.

\section{Conclusion}

Keeping in view the results obtained in the present study, the following conclusions may be drawn regarding the potential effectiveness of Ficus religiosa against dyslipidemia and proinflammatory markers: (I) an effective curative effect against the Total cholesterol, Triglyceride, and Very low density lipoprotein levels was exhibited by all the three doses of
Ficus religiosa with the most pronounced effect at $400 \mathrm{mg} / \mathrm{kg}$ dose. (II) Ficus religiosa in a dose of 400 milligram/kilogram significantly improved plasma HDL levels. (III) Ficus religiosa in a dose of 400 milligram/kilogram had nearly similar antihypercholesterolemic, LDL lowering, and HDL improving effect as that of the standard drug (Atorvastatin). (IV) Ficus religiosa lowers the level of inflammatory marker TNF- $\alpha$ in $100 \mathrm{mg}$ (Group II) and 200mg (Group III) dose \& significant reduction occurred in $400 \mathrm{mg}$ (Group IV) dose, which shows its anti-inflammatory action as well.

The results of the present study are encouraging and may reveal the importance of Ficus religiosa as an economical antihyperlipidemic agent. But, details of the complete mechanism have yet not been explored. Therefore, further experiments are required to elucidate the exact mechanism of action. Also, more specific and longer duration animal and human studies are required to further expand the existing therapeutic potential of Ficus religiosa and provide a convincing support to its future clinical use in modern medicine.

\section{Acknowledgements}

I would like to thank Dr. S. M. Natu, Professor, Pathology, King George's Medical University for his kind support. I am also thankful to the animal house staff Mr. Anil, Miss. Shama, Mr. Gulab, the laboratory technician Mr. Ashok and statistician Mr. Rajendra Misra of my department for their support and help.

\section{Consent for publication}

Written informed consent was obtained from the participants for the publication of this report.

\section{References}

1. (2010) Global status report on noncommunicable diseases. WHO, Geneva, UK.

2. Hulley SB, Rosenman RH, Bawol RD, Brand RJ (1980) Epidemiology as a Guide to Clinical Decisions. The Association between Triglyceride and Coronary Heart Disease. N Engl J Med 302(25): 1383-1389.

3. LaRosa JC, Hunninghake D, Bush D, Criqui MH, Getz GS, et al. (1990) The cholesterol facts. A summary of the evidence relating dietary fats, serum cholesterol, and coronary heart disease. A joint statement by the American Heart Association and the National Heart, Lung, and Blood Institute. The Task Force on Cholesterol Issues, American Heart Association. Circulation 81(5): 1721-1733.

4. Despres JP, Lemieux I (2006) Abdominal obesity and metabolic syndrome. Nature 444(7121): 881-887.

5. Costa J, Borges M, David C, Vaz Carneiro A (2006) Efficacy of lipid lowering drug treatment for diabetic and non-diabetic patients: metaanalysis of randomized controlled trials. BMJ 332(7550): 1115-1124.

6. Cannon CP, Steinberg BA, Murphy SA, Mega JL, Braunwald E (2006) Meta-analysis of cardiovascular outcomes trials comparing intensive versus moderate statin therapy. J Am Coll Cardiol 48(3): 438-445.

7. Brown BG, Stukovsky KH, Zhao XQ (2006) Simultaneous low-density lipoprotein-C lowers and high-density lipoprotein-C elevation for optimum cardiovascular disease prevention with various drug classes, and their combinations: a meta-analysis of 23 randomized lipid trials. Curr Opin Lipidol 17(6): 631-636. 
8. Powers AC (2008) Diabetes Mellitus. In: Fauci AS, Braunwald E, Kasper DL, Hauser SL, Longo DL, et al. (Eds.), Harrison's Principles of Internal Medicine (17 ${ }^{\text {th }}$ edn.), New York: McGraw-Hill. pp. 2275-2304.

9. Chitturi S, George J (2002) Hepatotoxicity of commonly used drugs: non-steroidal anti-inflammatory drugs, antihypertensives, antidiabetic agents, anticonvulsants, lipid- lowering agents, psychotropic drugs. Semin Liver Dis 22(2): 637-640.

10. Kameswararao B, Giri R, Kesavulu MM, Apparao C (1997) Herbal medicines: In the treatment of diabetes mellitus. Manphar Vaidya Patrika 1: 33-35.

11. K Shrestha, J Banerjee, A Shrestha (2015) Pharmacological properties, phytochemical screening and uses of medicinal plant Ficus religiosa Linn. (Moraceae). European Journal of Biomedical and Pharmaceutical sciences 2(3): 997-1010.

12. Vinutha B, Prashanth D, Salma K, Sreeja SL, Pratiti D, et al. (2007) Screening of selected Indian medicinal plants for acetylcholinesterase inhibitory activity. J Ethnopharmacol 109(2): 359-363.

13. Pandit R, Phadke A, Jagtap A (2010) Antidiabetic effect of Ficus religiosa extract in streptozotocin induced diabetic rats. J Ethnopharmacol 128(2): 462-466.

14. Kirana H, Jali MV, Srinivasan BP (2011) The study of aqueous extract of Ficus religiosa Linn. on cytokine TNF- $\alpha$ in type 2 diabetic rats. Phcog Res 3(1): 30-34.

15. Kumar KP, Reddy ARN, Reddy YN, Anbu J (2010) Lipid lowering activity of lercanidipine in hyperlipidemic rats. Iranian Journal of Pharmacology \& Therapeutics 9: 73-75.

16. Reeves PG, Nielsen FH, Fahey GC Jr (1993) AIN-93 purified diets of laboratory rodents: Final report of the American Institute of Nutrition Ad Hoc Writing Committee on the Reformulation of the AIN-76 Rodent Diet. J Nutr 123(11): 1939-1951.

17. Iona Lozano, Remmelt Van der Werf, William Bietiger, Seyfritz E, Peronet C, et al. (2016) High-fructose and high-fat diet-induced disorders in rats: impact on diabetes risk, hepatic and vascular complications. Nutr Metab (Lond) 13: 15.
18. Akhil Sanghal, KK Pant, SM Natu, A Nischal, S Khattri, et al. (2012) An Experimental Study to evaluate the preventive effect of Zingiber officinale (ginger) on Hypertension \& Hyperlipidemia and its comparison with Allium sativum (garlic) in Rats. Journal of Medicinal Plants Research 6(25): 4231-4238.

19. Khan MSA, Hussain SA, Jais AMM, Zakaria ZA, Khan M (2011) Antiulcer activity of Ficus religiosa stem bark ethanolic extract in rats. J of Medicinal Plants Research 5(3): 354-359.

20. Harold Bays, Lawrence, Mandarino, Ralph A De fronzo (2004) Mechanisms of endocrine disease. Journal of Clinical Endocrinology and Metabolism 89(2): 463-478.

21. Acer KF, Kuzman D, Seliska M, Pompon D, Rozman B (2007) TNFalpha interferes with lipid homeostasis and activates acute and proatherogenic processes. Physiological Genomics 31(2): 216-227.

22. Ouchi N, Kihara S, Funahashi T, Nakamura T, Nishida M, et al. (2003) Reciprocal association of CRP with adiponectin in blood stream and adipose tissue. Circulation 107(5): 671-674.

23. Wang HJ, Jin YX, Shen W, Neng J, Wu T, et al. (2007) Low dose streptozotocin (STZ) combined with high energy intake can effectively induce type 2 diabetes through altering the related gene expression. Asia Pac J Clin Nutr 16(1): 412-417.

24. Pradan A (2007) Obesity, Metabolic syndrome and Type 2 Diabetes mellitus: inf basis of glucose metabolic disorder. Nutrition rev 65(12): 152-156.

25. Sethi JK, Hotamisligil GS (1999) The role of TNF-alpha in adipocyte metabolism. Cell and development biology 10(1): 19-29.

26. Doumatey AP, Lashley KS, Huang H, Zhou J, Chen G, et al. (2010) Relationship among obesity, inflammation and insulin resistance in African Americans and West Africans. Obesity 18(3): 598-603.

27. Agarwal V, Chauhan BM (1988) A study on composition and hypolipidemic effect of dietary fibre from some plant foods. Plant Foods Hum Nutr 38(2): 189-197.

Your next submission with Juniper Publishers
will reach you the below assets
- Quality Editorial service
- Swift Peer Review
- Reprints availability
- E-prints Service
- Manuscript Podcast for convenient understanding
- Global attainment for your research
- Manuscript accessibility in different formats
( Pdf, E-pub, Full Text, Audio)
- Unceasing customer service
Track the below URL for one-step submission
https://juniperpublishers.com/online-submission.php

